\title{
MAPEAMENTO DE COMPETÊNCIAS DIGITAIS: A INCLUSÃO SOCIAL DOS IDOSOS
}

\begin{tabular}{c} 
DIGITAL MAPPING SKILLS: \\
SOCIAL INCLUSION OF THE ELDERLY \\
\hline MAPEO DE LAS COMPETENCIAS DIGITALES: \\
INCLUSIÓN SOCIAL DE LAS PERSONAS MAYORES \\
Leticia Rocha Machado \\
Tássia Priscila Fagundes Grande \\
Patricia Alejandra Behar \\
Fabiana de Miranda Rocha Luna
\end{tabular}

\section{RESUMO}

O presente artigo apresenta o mapeamento de competências digitais de idosos em cursos de inclusão digital. Estes buscam cada vez mais acompanhar a transformação tecnológica, o que permite uma investigação sobre as competências digitais dos idosos no uso destes recursos. Portanto, a pesquisa se caracteriza como qualiquantitativa e foi desenvolvida a partir de 3 etapas: 1) Construção do Referencial Teórico; 2) Curso de extensão; 3) Coleta e análise dos dados. Para a terceira etapa foram utilizados três instrumentos: questionários com perguntas abertas e fechadas e observação participante. O público-alvo foram 31 idosos com idade igual ou superior a 60 anos que participaram de um curso de inclusão digital ofertado em uma Universidade Federal. Todos assinaram o Termo de Consentimento Informado. Os dados possibilitaram o mapeamento de cinco competências, categorizada em três grupos de competências: Alfabetização digital, Letramento digital, Fluência digital. As principais competências que apareceram nestas categorias foram: Recursos básicos da internet; Pesquisa na Web; Comunicação através do e-mail; Informação online confiável e Resiliência Virtual. Os resultados possibilitaram inferir que os idosos que participaram do curso estão abertos a novas aprendizagens e, principalmente, são extremamente motivados para continuar aprendendo sobre as tecnologias digitais em geral.

PALAVRAS-CHAVE: Competências. Inclusão digital. Idosos.

\begin{abstract}
This article maps the digital skills of the elderly in digital inclusion programs. These increasingly seek to follow the technological transformation, which allows an investigation into the digital skills of the elderly in the use of these resources. Therefore, the research is characterized as qualitative and quantitative, and was developed from three steps: 1) Construction of Theoretical Framework; 2) Extension course; 3) collection and analysis of data. For the third step three instruments were used: questionnaires with open and closed questions and participant observation. The audience were 31 elderly aged over 60 years who participated in a digital inclusion course offered in a Federal University. All signed the informed consent form. The data allow mapping five skills, categorized in three groups of skills: digital literacy, digital literacy, digital fluency. The main skills that appeared in these categories were: basic Web resources; Web Search; Communication via e-mail; reliable online information and Virtual Resiliency. The results allowed to infer that the elderly who attended the course are open to new learning and, especially, are extremely motivated to continue learning about digital technologies in general.
\end{abstract}

KEYWORDS: Skills development. Digital divide. Elderly.

\section{RESUMEN}

Este artículo presenta un mapeamento de competencias digitales de idosos en programas de inclusión digital. Estos buscan, cada vez más, acompañar la transformación tecnológica y eso permite desarrollar un estudio sobre las competencias digitales de este tipo de publico usando estos recursos. Por lo tanto, la investigación se caracteriza por ser cualitativa y cuantitativa, y se desarrolla a partir de tres etapas: 1) Construcción del marco teórico; 2) Curso de Extensión; 3) Colecta y análisis de datos. Para el tercer paso se utilizaron tres instrumentos: 
cuestionarios con preguntas abiertas y cerradas y observación participante. Participaron 31 ancianos mayores de 60 años en un curso de inclusión digital que se ofrece en la Universidad Federal do Rio Grande do Sul, Brazil. Todos firmaron el formulario de consentimiento informado. Los datos permiten el mapeo de cinco competencias, categorizados en tres grupos: alfabetización digital, literacia digital y la fluencia digital. Las principales competencias identificadas en estas categorías fueron: recursos Web básicos; Búsqueda en la web; La comunicación a través del correo electrónico; información confiable y resilencia virtual. Los resultados permitieron inferir que los ancianos que asistieron al curso están abiertos a nuevos aprendizajes y, sobre todo, son muy motivados para seguir aprendiendo acerca de las tecnologías digitales en general.

PALABRAS-CLAVE: Habilidades. Inclusión Digital. Anciano.

\section{INTRODUÇÃO}

O uso das tecnologias digitais já é uma realidade no cotidiano das pessoas. Estas são utilizadas tanto para o trabalho quanto para estudo e entretenimento pelos mais diversos públicos. O interesse, e a necessidade, em lidar com a tecnologia é algo latente na sociedade contemporânea e requer atenção, inclusive no que se refere aos processos educativos.

Ao longo da vida as pessoas continuam se desenvolvendo cognitivamente e construindo novos conhecimentos (FREIRE, 1993; MARTIN, 2007). Este processo requer, no seu cotidiano, diferentes saberes que são empreendidos em ações para a solução dos problemas vivenciados, incluindo o uso das tecnologias digitais. Neste sentido, as competências se apresentam como alternativa para mobilização destes saberes. A competência é a interlocução de três elementos (Conhecimento, Habilidade e Atitudes), com o objetivo de resolver determinada situação problema enfrentado pelo indivíduo em diferentes circunstâncias do seu dia-a-dia (BEHAR, 2013; PERRENOUD, 2013). Portanto, entende-se que pessoas mais velhas tem potencial para construir e também aprimorar competências para o uso das Tecnologias de Informação e Comunicação (TIC), em especial as tecnologias digitais.

Uma possibilidade para ampliar e/ou aprimorar as competências digitais é através do uso de materiais educacionais, como é o caso dos objetos de aprendizagem (OA). Nesta abordagem, objeto de aprendizagem é conceituado como qualquer material digital que possui uma finalidade educacional (AGUIAR; FLÔRES, 2014). Existem vários tipos de OA, podendo citar como exemplos os vídeos, animações, sites etc. (MACHADO, 2013).

Portanto, este artigo pretende apresentar o mapeamento de competências digitais realizado em um curso de inclusão digital para idosos. Para a investigação utilizou-se um objeto de aprendizagem em uma oficina ofertada para 31 idosos na Universidade Federal do Rio Grande do Sul/UFRGS no Brasil.

Um estudo realizado pelo Centro de Estudos sobre as Tecnologias da Informação e da Comunicação (Cetic.br, 2014) apontou um percentual baixo (14\%) no Brasil de usuários que utilizam o computador na faixa etária dos 60 anos ou mais. Este dado mostra a necessidade de ofertas de cursos para o ensino e a aprendizagem destas tecnologias. A cada ano surgem cursos de inclusão digital para idosos são ofertados para sanar as dúvidas deste 
público em relação ao uso destes recursos. No entanto, os cursos de inclusão digital ainda estão preocupados com questões técnicas no uso das tecnologias, desconsiderando os aspectos educacionais e sociais que deveriam permeá-los. Neste sentido, o estudo sobre as competências na inclusão digital de idosos é necessário para que seja possível o desenvolvimento integral do sujeito no uso das tecnologias digitais.

Nesta perspectiva, o artigo tem, inicialmente, uma sessão que delineia o atual panorama dos cursos de inclusão digital de idosos no Brasil, seguido da sessão sobre o conceito de competência, em específico as digitais, para o público mais velho. Em seguida é abordada a metodologia adotada nesta pesquisa, bem como os resultados coletados e as considerações finais encontradas.

\section{INCLUSÃO DIGITAL DE IDOSOS: PANORAMA BRASILEIRO}

O público idoso busca, cada vez mais, uma melhor qualidade de vida, ou seja, formas de interagir com o novo e com outras pessoas através da participação de grupos sociais, viagens, trabalho voluntário, cursos de diferentes temas etc.

A inovação tecnológica é uma das principais mudanças pelas quais a sociedade vem passando ao longo dos anos. A partir da necessidade de investigar sobre a inclusão dos idosos no meio tecnológico e comunicacional, surgem possibilidades de cursos de informática voltados para este público. Neste cenário novos desafios relacionados à formação continuada do público mais velho emergem, principalmente no uso das tecnologias digitais.

A educação é uma alternativa que possibilita a inserção dos idosos na atual sociedade tecnológica, pois propicia a oferta de diferentes metodologias de ensino que poderiam auxiliar os mais velhos (DOLL et al, 2015). A educação permanente ocorre em toda extensão da vida, não existindo uma fase específica para aprender (MARTIN, 2007).

Atualmente as instituições públicas e privadas têm aumentado suas ofertas de cursos visando atingir o interesse do público mais velho. Existem poucos estudos na área da inclusão digital para terceira idade que abordam suas reais necessidades, em comparação ao crescimento e inserção das tecnologias na sociedade. Alguns autores tratam sobre a inclusão digital de idosos, onde destacam a importância da inclusão social neste tipo de curso (SALES, 2009; KACHAR, 2010; DOLL, MACHADO, 2011; KACHAR, 2003; GANDRA, 2012; SILVA et al, 2014; CAVALCANTE et al, 2015). A interação com os recursos tecnológicos pode proporcionar o desenvolvimento de algumas competências ainda pouco estudadas (BEHAR, 2010). Esta temática aparece em muitas obras, trazendo exemplos de estratégias educacionais com possível aplicação nos cursos de informática para o público mais velho (SILVEIRA; KÜMPEL; ROCHA; PASQUALOTTI; COLUSSI, 2001; FILHO, 2003; CARVALHO et al, 2014;). 
A inclusão digital pode proporcionar uma maior segurança na autonomia no uso das tecnologias. Acompanhar a evolução das TIC é para os "jovens" de consciência e não para apenas os "jovens" de idade, pois a idade cronológica não importa (KACHAR, 2013; CARVALHO, ISHITANI, 2013).

Os idosos aprimoram a saúde mental e desenvolvem competências ao manusear novas ferramentas, muitas vezes relacionadas à comunicação, como chats, e-mails, grupos de discussões, etc. (BEHAR, 2010). Este tipo de experiência proporciona o sentimento de valorização, de reconhecimento sobre suas opiniões, melhorando assim, sua qualidade de vida.

Segundo Scoralick-Lempke, Barbosa, e Mota,

[...] o desenvolvimento de pesquisas que avaliem a contribuição de programas que visem à manutenção e à otimização das habilidades cognitivas, emocionais e sociais, próprias de um envelhecimento saudável, deve ser uma prioridade nas áreas que estudam a senescência [...] $(2012$, p. 776).

Portanto, atualmente, há uma necessidade de investigar o processo de ensino e aprendizagem em cursos de inclusão digital, a fim de propor soluções e/ou problematizar a inserção social deste público na atual sociedade. Ou seja, pontuar referencial teórico e metodológico sobre o tema no intuito de desenvolver competências referentes às tecnologias digitais e que venham a permitir a inclusão dos idosos na sociedade.

Competências digitais de idosos ainda é um tema pouco abordado e este fator impulsionou, em parte, este estudo. O crescimento da procura dos idosos por atualizações e informações na área das tecnologias digitais é também relevante para a presente pesquisa. Desta forma, considera-se necessário o mapeamento de competências digitais que seriam indispensáveis em uma perspectiva inclusiva social, cultural e tecnológica.

Uma das possibilidades de desenvolver e/ou aprimorar as competências digitais é através do uso de objetos de aprendizagem, conforme será apresentado a seguir.

\section{OBJETOS DE APRENDIZAGEM PARA IDOSOS}

A inclusão digital de idosos e o desenvolvimento de competências para o uso das tecnologias digitais requerem reflexões sobre os recursos digitais com viés pedagógico. Destaca-se a importância que tais recursos possuem ao apoiar os processos de aprendizagem de forma a contribuir com a mobilização dos aspectos cognitivos necessários a este contexto.

Os referidos recursos são conhecidos como Objetos de Aprendizagem (OA), cuja sua utilização 
[...] remete a um novo tipo de aprendizagem apoiada pela tecnologia, no qual o professor abandona o papel de transmissor de informação para desempenhar um papel de mediador favorecendo, assim, o processo de ensino e aprendizagem. $\mathrm{O}$ professor pode propiciar condições favoráveis às trocas e à cooperação, oferecendo ao aluno situações problema e valorizando a produção de novos conhecimentos (MACHADO, LONGHI, BEHAR, 2013, p. 62).

Objetos de aprendizagem específicos para idosos são pouco desenvolvidos. Os OA encontrados são portais que apresentam notícias e informações que envolvem o processo de envelhecimento, como é o caso do Portal da Terceira Idade (http://www.portalterceiraidade.com.br/). No uso das TIC foram encontrados objetos específicos para o público idosos desenvolvidos em uma tese de doutorado ${ }^{1}$. Além destes objetos não foram encontrados outros em repositórios de OA, como os conhecidos MERLOT (http://www.merlot.org/merlot/index.htm) e o Banco Internacional de Objetos Educacionais (http://objetoseducacionais2.mec.gov.br/).

Portanto, a inclusão digital de idosos está carente de tais recursos. Para que o processo de ensino e aprendizagem, envolvendo pessoas mais velhas e as tecnologias digitais seja cada vez mais qualificado é importante a construção destes para este público. Nesta perspectiva, os OA podem se tornar aliados imprescindíveis em processos de ensino e aprendizagem para a construção de competências tecnológicas.

\section{DEFINIÇÃO E CONCEITOS DE COMPETÊNCIAS DIGITAIS PARA IDOSOS}

As competências são muito discutidas atualmente em diferentes áreas como educação, administração entre outras. Dessa forma, o entendimento sobre o conceito apropriado à presente discussão se faz necessário devido à complexidade do termo e aos seus significados, que são múltiplos (PERRENOUD,1999).

Neste artigo é abordado o conceito de competências como a mobilização conjunta de recursos cognitivos específicos (mas não fixos ou exclusivos de determinada competência) para enfrentar as mais diversas situações problemas. Para tanto, é importante a relação de três elementos: conhecimentos, habilidades e atitudes (CHA). Tais recursos estão respectivamente ligados ao saber (conhecer), saber fazer e saber ser.

Para Perrenoud (1999, p.4) os conhecimentos "são representações da realidade, que construímos e armazenamos ao sabor de nossa experiência e de nossa formação". Já o saber fazer (habilidade), ainda segundo o mesmo autor, "é uma "inteligência capitalizada", uma sequência de modos operatórios, de analogias, de intuições, de induções, de deduções, de transposições dominadas, de funcionamentos heurísticos rotinizados que se tornaram

\footnotetext{
${ }^{1}$ Os objetos estão disponíveis no site: 〈http://idosos.weebly.com/objetos-de-aprendizagem.html〉.
} 
esquemas mentais de alto nível ou tramas que ganham tempo, que 'inserem' a decisão" (PERRENOUD, 1999, p.33; PERRENOUD, 2013). Para Behar et al (2013, p.29) o saber ser (atitude) é "o modelo mental do sujeito, seus valores e crenças. Sintonizam-se com as intenções, desejos e vontades do indivíduo (2013). Por meio desse elemento, a competência se concretiza, pois significa a prontidão para agir".

Nesse sentido, pretende-se abordar as competências que podem ser desenvolvidas e/ou aprimoradas, bem como os recursos específicos (CHA) mobilizados por idosos no uso das TIC, em específico a internet.

\section{COMPETÊNCIAS DIGITAIS PARA IDOSOS}

Aprender e buscar atualizações na área das tecnologias digitais tornou-se praticamente indispensável devido ao avanço e desenvolvimento na sociedade. Esta realidade também se aplica ao público idoso, pois o uso destas tecnologias é imprescindível em ações rotineiras, principalmente no que se refere à comunicação e acesso a informações em geral.

$\mathrm{Na}$ velhice as interações sociais são essenciais, e atualmente, uma parte significativa destas interações, acontece virtualmente. Assim sendo, uma educação permanente que propicie aos idosos a inclusão no meio digital pode possibilitar a sensação de participar da sociedade, criando novas relações sociais e afetivas.

A interação com recursos tecnológicos digitais proporciona o desenvolvimento das capacidades de imaginação, memorização e de empregar estratégias de comunicação, favorecendo o desenvolvimento de competências diferentes das utilizadas normalmente (BEHAR, 2010). Mesmo sendo uma temática pouco abordada, alguns estudos definem competência digital como a capacidade de pesquisar, analisar e avaliar informação por meio da internet ou meio digital (SANTOS, 2008).

Pereira e Neves (2011) abordaram o assunto sobre as competências da inclusão digital de idosos frisando que existem benefícios para a qualidade de vida dos idosos nesta modalidade, mas não elencaram e detalharam sobre possíveis competências. Outros autores também abordam a temática sobre competências digitais ou tecnológicas em seus trabalhos (VECHIATO, 2010; PEREIRA, NEVES, 2011; PINHO, 2012; DIAS, 2012; PETRELLLA, PINTO, PEREIRA, 2014).

A falta de literatura sobre o tema provoca reflexão sobre quais seriam as competências digitais que poderiam ser desenvolvidas e/ou aprimoradas com os idosos. Partindo do estudo realizado por Machado e Behar (2013) é possível indicar três competências essenciais e que deveriam ser desenvolvidas em cursos de inclusão digital. São elas:

- Alfabetização digital: conceito que equivale a necessidade de dominar funcionalmente as tecnologias, leitura e escrita para possuir acesso ao conhecimento digital e virtual (COLL, ILLERA, 2010). 
- Letramento digital: é a competência que está relacionada com a pesquisa, avaliação, reflexão e criticidade das informações disponíveis na internet, bem como o uso das ferramentas digitais.

- Fluência digital: está intimamente relacionada tanto com o conceito de alfabetização como com o de letramento digital. O sujeito será fluente digital somente se for além do ato de saber buscar um texto, ler, escrever, salvar e enviar um documento por meio de tecnologias digitais, ou seja, ser crítico em relação ao seu uso de forma a combinar o uso de diferentes ferramentas digitais.

Nesta perspectiva, a seguir será detalhada a metodologia adotada, bem como suas etapas para responder ao objetivo desta investigação.

\section{METODOLOGIA}

Para responder ao objetivo deste artigo que foi de mapear as competências digitais dos idosos no uso dos recursos da Internet, esta pesquisa se caracterizou como uma pesquisa quali-quantitativa, de cunho interpretativo. Além do mapeamento das competências também foi necessário o aprofundamento dos seus elementos (Conhecimentos, Habilidade e Atitudes).

Para atender ao objetivo, o público-alvo desta investigação foi 31 idosos com idade igual ou superior a 60 anos que participaram do curso de inclusão digital IDI-UFRGS: Inclusão Digital de Idosos da Universidade Federal do Rio Grande do Sul. O curso ofertado no início de março de 2014 utilizou a mídia impressa (jornal local) no intuito de proporcionar 40 vagas para participantes que se inscreveram através do contato telefônico informado no anúncio.

O referido curso, ofertado de forma gratuita, teve por objetivo o uso do computador e suas ferramentas com a finalidade de desenvolver e/ou aprimorar três grupos de competências: Alfabetização digital, Letramento digital, Fluência digital (Figura 1). Cada conjunto possuía outras competências específicas.

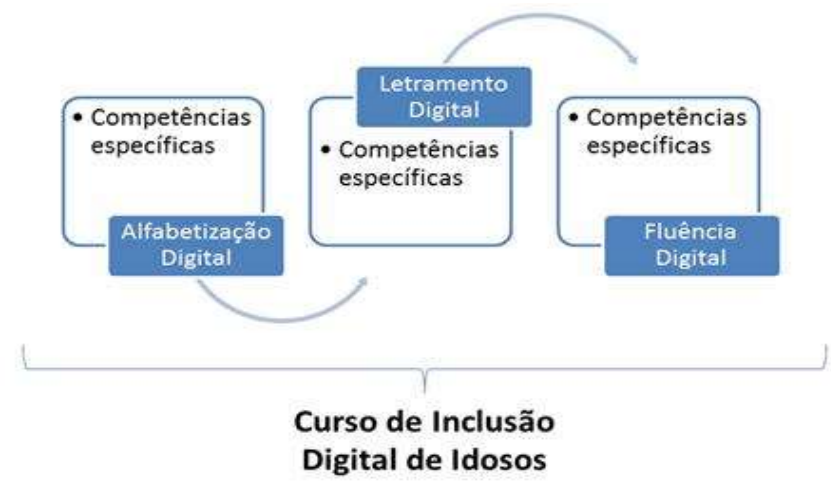

FIGURA 1 - Competências digitais para cursos de inclusão digital de idosos Fonte: As autoras (2015) 
O IDI-UFRGS foi realizado em 3 módulos. O módulo inicial, finalizado no primeiro semestre de 2014, ofereceu subsídios no que se refere à iniciação ao computador e seus periféricos, seguido da edição de texto e finalizando com a introdução da internet que inclui entrar em sites, realizar pesquisa e utilizar o e-mail (abrir, enviar, responder, encaminhar e anexar). As aulas tiveram duração de 2 horas semanais, inteirando 30 horas por semestre. Ao total o curso possui duração de 2 anos.

Durante o primeiro módulo foram utilizados objetos de aprendizagem, entre eles o ConReDis: Construção de Redes sociais Digitais para Idosos. Este OA possui dois eixos: Internet e Redes Sociais. Para o primeiro módulo do curso de inclusão digital foi utilizado apenas o eixo 1: Internet. Ou seja, o referido objeto serviu de base como meio para vincular os conteúdos e atividades, propiciando elementos para desenvolver as competências pretendidas para o módulo 1 do curso. Desta forma, nesta pesquisa participaram 31 idosos com média de idade de 67. Considerando o total de idosos, apenas 24 são do sexo feminino e 7 do sexo masculino.

Para a coleta de dados foram utilizados três instrumentos:

a) questionário com perguntas abertas e no qual foi aplicado no inicio do curso. O propósito deste questionário foi investigar os conhecimentos que os participantes possuíam no que tange o uso do computador e suas ferramentas;

b) questionário fechado com escala likert. $\mathrm{O}$ objetivo deste questionário foi de mapear as competências dos alunos através dos Conhecimentos, Habilidade e Atitudes no que tange o uso da Internet e suas ferramentas (eixo 1 do ConReDis). O referido instrumento foi aplicado no final do primeiro semestre do curso;

c) observação participante que foi realizada pelas pesquisadoras durante as aulas de inclusão digital.

Os dados de natureza qualitativa foram analisados a partir das orientações de Bardin (2010). Para a autora, a análise de conteúdo é "um conjunto de técnicas de análise das comunicações, que utiliza procedimentos sistemáticos e objetivos de descrição de conteúdos das mensagens" (BARDIN, 2010, p.38). Bardin (2010) sugere as seguintes etapas de análise: a) Pré-análise: prima pela organização do material coletado, referindo-se à escolha dos documentos e à formulação das hipóteses e dos objetivos; b) Leitura exploratória do material, compreendendo a leitura global das questões e leituras sucessivas referentes aos dados individuais, refere-se à codificação, decomposição ou enumeração dos materiais; c) Tratamento dos dados obtidos a partir da identificação dos descritores (unidades de registro), com posterior categorização e interpretação dos dados.

Já os dados quantitativos foram ponderados por meio da distribuição de frequência representada em média e desvio padrão. $\mathrm{Na}$ análise dos escores do $\mathrm{CHA}$ foram utilizados os dados estatísticos descritivos e as inferências para a comparação das médias dos escores de cada elemento da competência, considerando as categorias das variáveis como independentes. A seguir serão apresentados os resultados coletados, bem como a discussão teórica. 


\section{ANÁLISE E DISCUSSÃO DOS DADOS COLETADOS}

O curso de inclusão digital de idosos IDI-UFRGS possibilitou a coleta de dados no que tange o mapeamento de competências digitais de idosos na aprendizagem da informática e suas ferramentas e/ou recursos. Inicialmente os idosos apontaram quais seriam as competências necessárias, na sua perspectiva, para utilizar as ferramentas da internet. Estes apontamentos foram categorizados em Conhecimentos, Habilidades e Atitudes, conforme o quadro abaixo:

QUADRO 1 - Conhecimento, Habilidades, Atitudes apontadas, inicialmente, pelos idosos.

\begin{tabular}{|c|c|c|}
\hline \multicolumn{3}{|c|}{ Competência no Uso da Internet } \\
\hline Conhecimentos & Habilidades & Atitudes \\
\hline $\begin{array}{l}\text {-Saber o básico para poder } \\
\text { usar; } \\
\text {-Conhecer idioma inglês e } \\
\text { outros; } \\
\text { Conhecer mais para ter } \\
\text { liberdade escrita na internet. }\end{array}$ & $\begin{array}{l}\text { - Arrumar galerias de fotos; } \\
\text {-Utilizar meio de comunicação; } \\
\text {-Efetuar compras; } \\
\text {-Mandar e receber mensagens; } \\
\text {-Pesquisar; } \\
\text {-Falar com pessoas de longe; } \\
\text {-Ver receitas para fazer; } \\
\text {-Anexar figuras ou fotos; } \\
\text {-Ler notícias; } \\
\text {-"Macetes” para facilitar o uso; } \\
\text {-Localizar lugares (virtual) onde haja mais } \\
\text { cursos. }\end{array}$ & $\begin{array}{l}\text {-Ajudar meus netos nas } \\
\text { pesquisas; } \\
\text { Curiosidade; } \\
\text {-Vontade própria para } \\
\text { pesquisa; } \\
\text {-Criatividade; } \\
\text {-Tranquilidade. }\end{array}$ \\
\hline
\end{tabular}

Fonte: As autoras (2016).

Os participantes assinalaram alguns fatores biopsicossociais que podem interferir na aprendizagem e uso das ferramentas da internet, como é o caso de: Enxergar bem; Boa visão; Desenvolver a memória; Memória para fixar os passos para fazer determinada coisa. Desta forma, os idosos avaliaram o desenvolvimento e/ou aprimoramento das competências durante a participação do primeiro módulo do curso IDI-UFRGS.

A partir desta análise e das observações participantes, foi possível mapear as competências digitais específicas da internet, bem como os seus elementos constituintes (Conhecimentos, Habilidades e Atitudes). A observação participante possibilitou um conhecimento aprofundado sobre as competências que os idosos já possuíam, bem como suas 
dificuldades no manuseio do computador e seus recursos. As principais que apareceram foram:

a) Recursos básicos da Internet- corresponde a iniciação do uso das ferramentas e recursos da internet, como entrar em um navegador, digitar o endereço de um site etc.;

b) Pesquisa na Internet - está relacionada com a escolha de um site de pesquisa, bem como a escolha de expressões para realizar a pesquisa entre outros;

c) Informação online confiável - consiste na análise crítica da informação disponibilizada e criada no virtual;

d) Comunicação através do e-mail - corresponde a abrir, enviar, encaminhar um e-mail;

e) Resiliência virtual - está relacionado com a capacidade de enfrentar as dificuldades provenientes do uso das ferramentas digitais e saber utilizar as suas limitações biopsicossociais a seu favor na aprendizagem.

Como os dados referentes às competências (Figura 2) foi possível analisar que este grupo de idosos que participam do curso estão abertos a novas aprendizagens e, principalmente, são extremamente motivados a continuar a aprender sobre internet. Isso também foi possível analisar durante as aulas através das observações participantes, uma vez que houve um índice baixo de desistência (23\%) comparado com o relato de outros estudos sobre inclusão digital de idosos. Outro fator observado foi o interesse dos idosos em relação à expectativa que a Internet possibilita para a comunicação online com familiares, amigos etc.

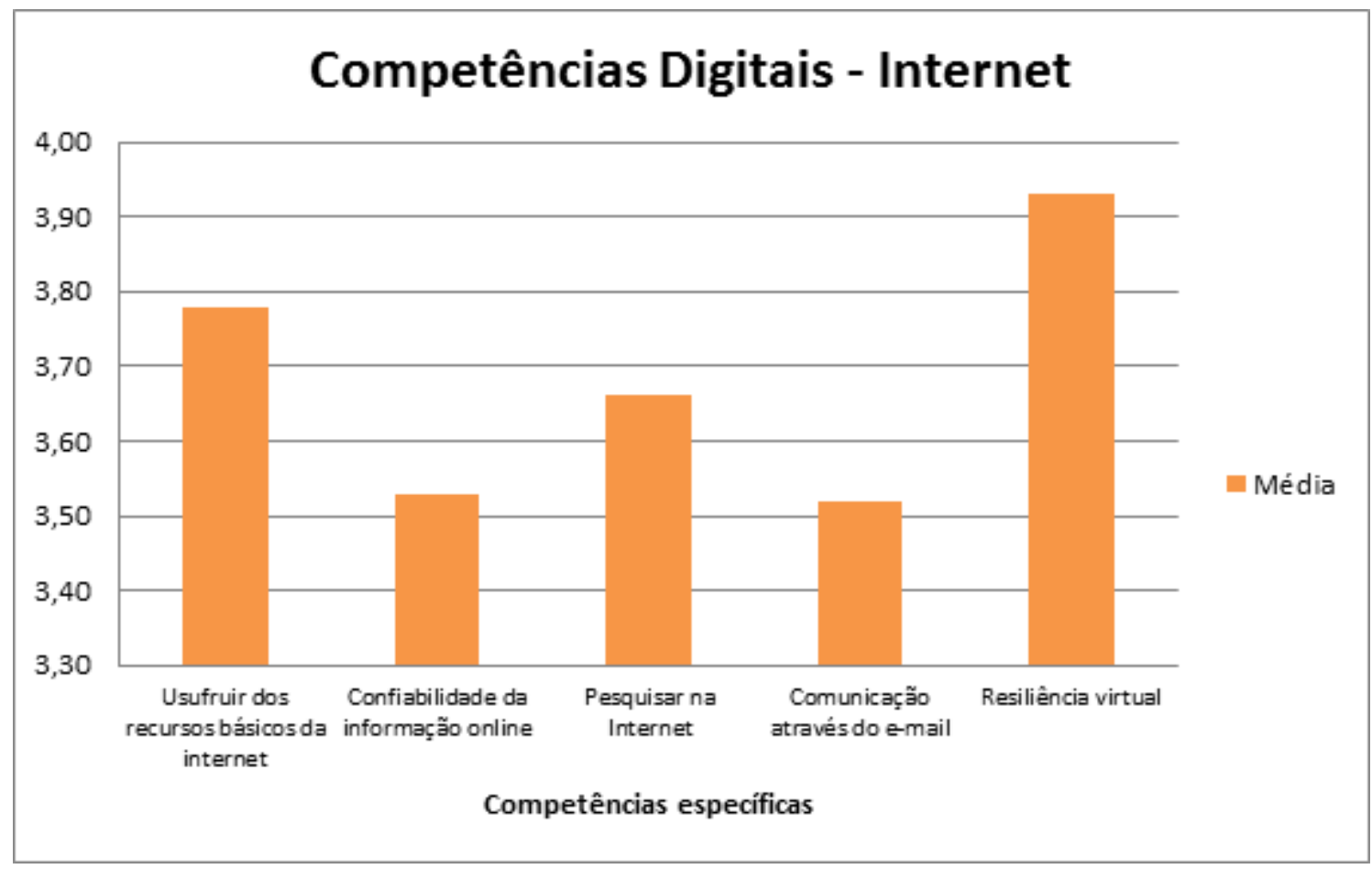

FIGURA 2 - Comparação entre as competências digitais específicas da internet.

Fonte: As autoras (2016) 
A partir da análise do gráfico (Figura 2) comparativo entre as competências específicas é possível notar que a Resiliência digital teve uma média $(3,92)$ superior às outras. Esta se refere ao compreender e saber utilizar a seu favor as limitações biopsicossociais na internet foi apontado como a mais desenvolvida e/ou aprimorada durante o curso. Durante as observações participantes foi possível perceber as limitações dos idosos no uso das tecnologias que era superado pelas suas experiências de vida traduzidas em metáforas que auxiliavam na aprendizagem dos recursos tecnológicos.

A resiliência ainda é um campo pouco estudado no Brasil, principalmente com os idosos. Na educação a resiliência é utilizada como uma capacidade de adaptar-se as mudanças que estão ocorrendo, pensar, repensar e autoavaliar as atitudes, valores, conhecimentos e buscar se desenvolver individualmente e coletivamente (TAVARES, 2001). No contexto dos idosos no uso dos recursos e ferramentas da internet é primordial, já que muitos ainda não estão abertos ao novo, ou mesmo não realizaram uma autoavaliação para se transformar e reavaliar o seu processo de aprendizagem.

No intuito de analisar as competências de forma individual é importante refletir sobre os Conhecimentos, Habilidade e Atitudes de forma separada, conforme o gráfico (Figura 2) e tabela abaixo (Tabela 1).

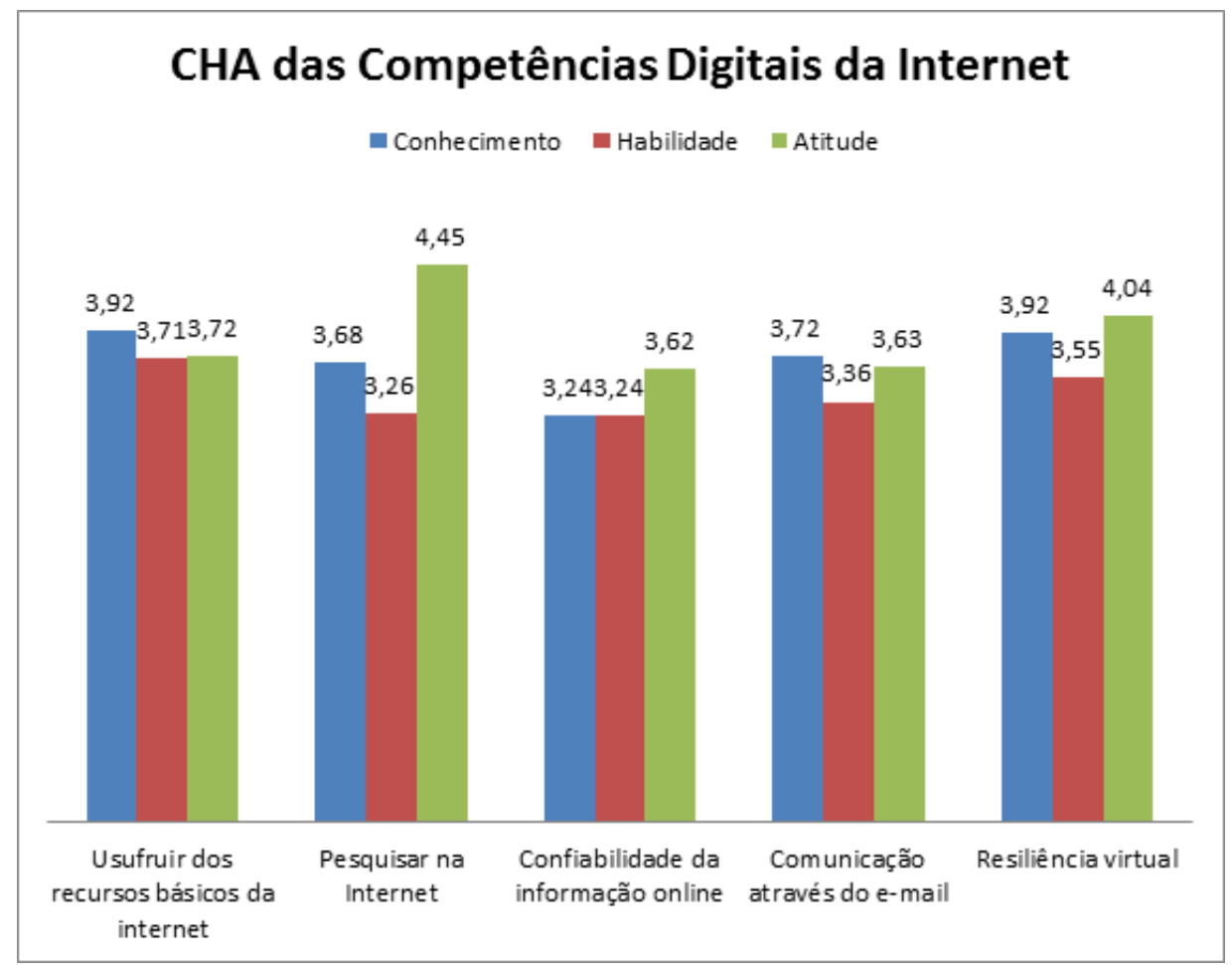

FIGURA 02 - Comparação entre os Conhecimentos, Habilidades e Atitudes das competências digitais específicas da internet.

Fonte: As autoras (2015) 
O gráfico acima aponta que a atitude é avaliada com uma média alta, indicando que os participantes possuem uma motivação, autoconfiança e responsabilidade no que tange a auto avaliação da sua aprendizagem, corroborando com os dados apontados no alto índice da competência Resiliência digital conforme já descrito (Tabela 1).

TABELA 1 - CHA das Competências Digitais da Internet para idosos

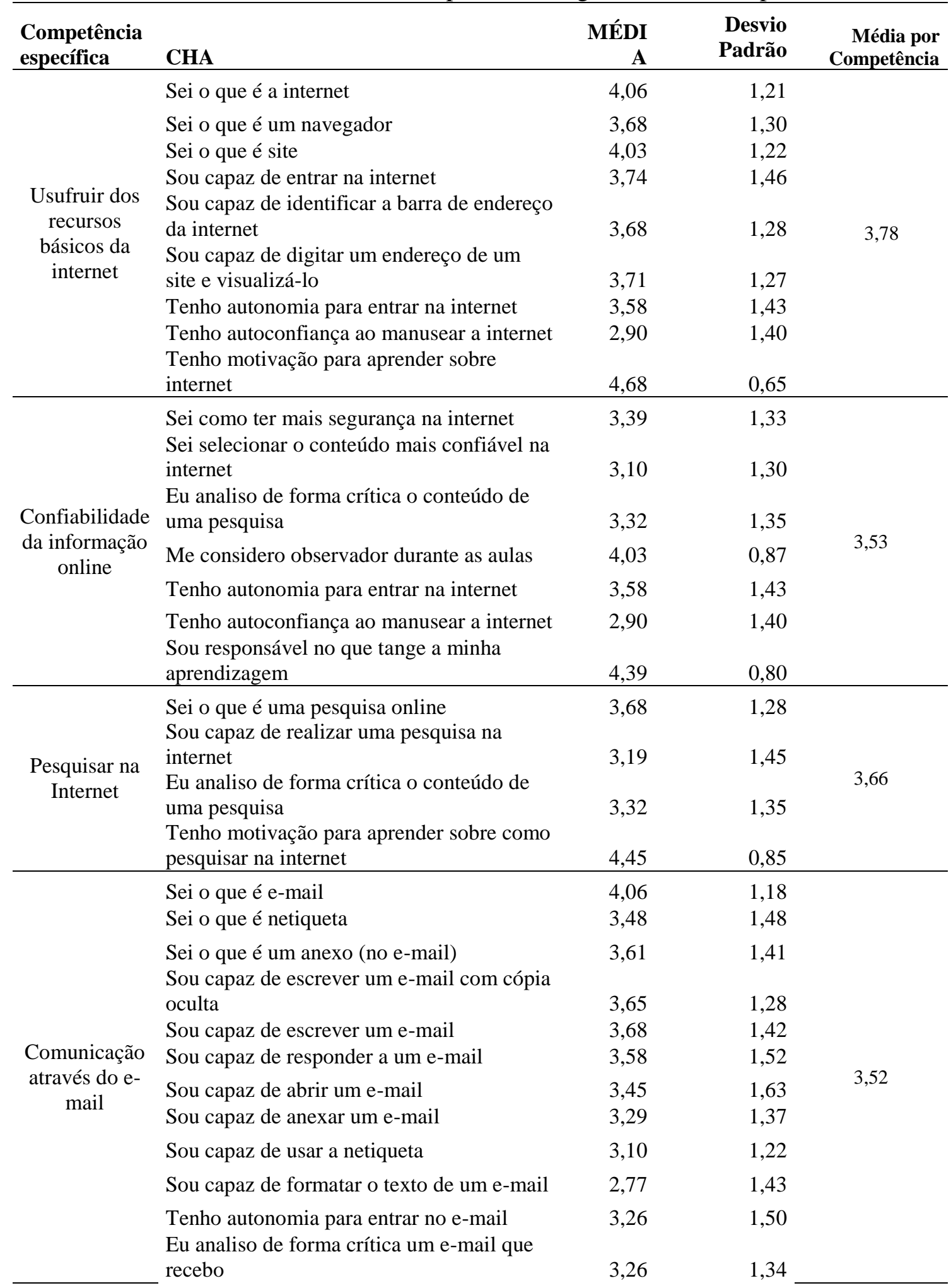




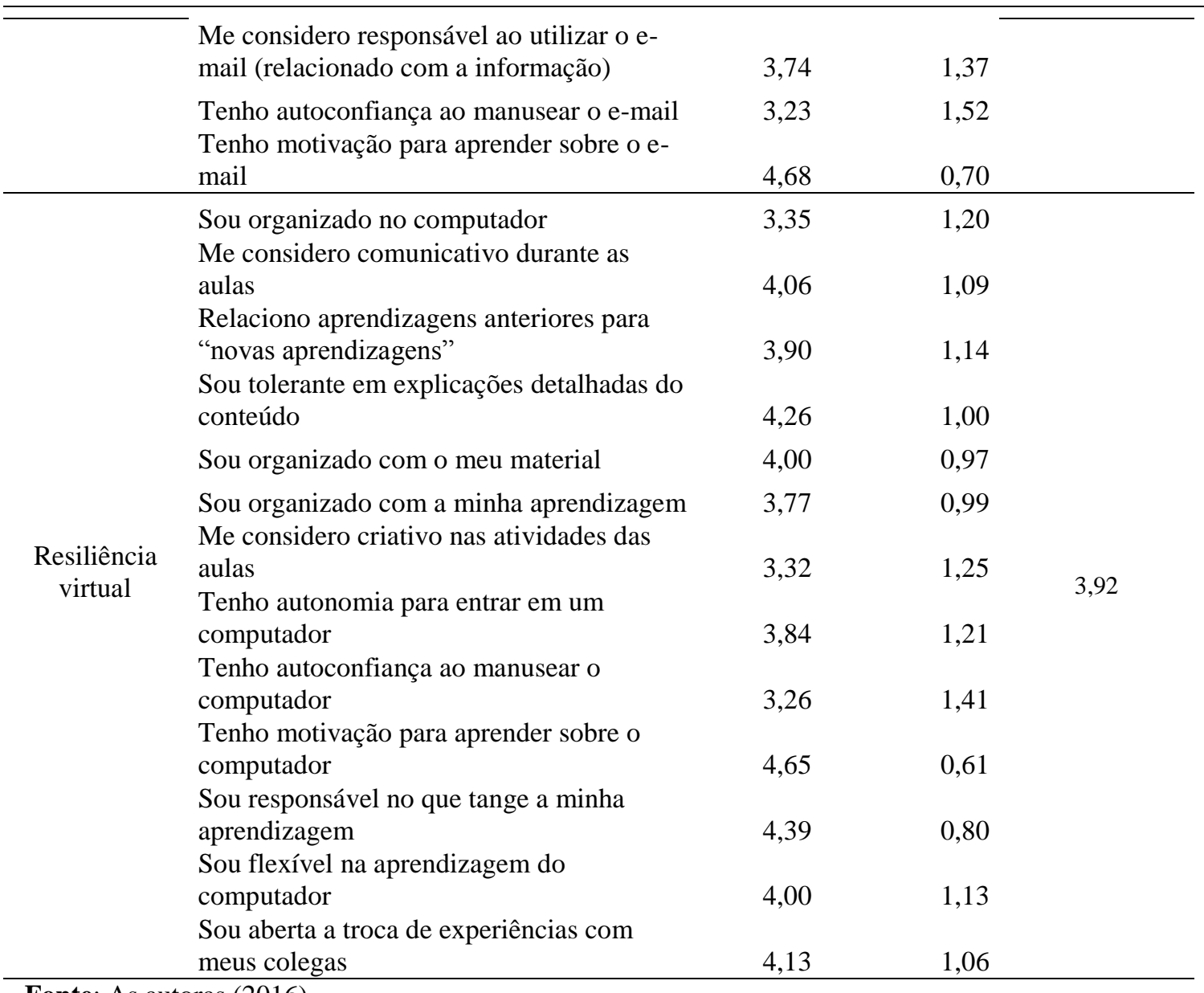

Fonte: As autoras (2016).

O curso IDI-UFRGS assume um grande significado perante os idosos e lhes proporciona satisfação e orgulho por participarem de um curso ofertado em uma Universidade Federal, refletindo diretamente na percepção de sua autoimagem e, principalmente no reconhecimento da família e amigos pelo seu êxito no uso das ferramentas digitais. Os participantes, conforme observado durante o curso, se manifestam interessados e mostram o aprendizado construído durante o curso para os familiares através, por exemplo, do envio de e-mail ou mesmo em frases como: "Agora vou usar o comutador sem precisar dos meus filhos", ou "Os netos irão ver o que sou capaz". Esse dado também e apontado em outras pesquisas como a da autora Machado (2007).

As médias baixas apontadas nas competências se referem muito ao conhecimento, conforme a figura 3. Estes dados remete à avaliação do objeto de aprendizagem ConReDis, apontando a necessidade de revisar a forma de escrita e apresentação do conteúdo disponibilizado. Durante a utilização do material em aula verificou-se, por exemplo, a adequação do material de apoio que se apresentou rápido para os usuários mais velhos. Todas estas análises já foram considerados para a remodelação do OA ConReDis.

Já em relação às habilidades a média também se apresentou baixa (figura 3). Este dado está relacionado com a falta de uso fora da aula. Muitos alunos ainda não possuem 
acesso a um computador, dificultando, assim, a revisão e repetição da aprendizagem realizada durante o curso. $\mathrm{Na}$ aula percebe-se que aqueles idosos que fazem anotações possuem mais facilidade no manuseio do computador. Esta facilidade também se reflete naqueles usuários mais velhos que utilizam com frequência os materiais extras e refazem as atividades propostas em aula. Isto só é possível devido a disponibilidade do ConReDis de forma virtual através de um endereço online.

Por final o quadro 2 abaixo consiste em um resumo da matriz de competências mapeadas no que diz respeito à aprendizagem básica das ferramentas e recursos da internet a partir dos dados discutidos na presente investigação. Ressalva-se que é de extrema importância que o professor propicie a construção do conhecimento de forma que o computador possa servir como um instrumento inclusivo e não exclusivo na sociedade.

\section{QUADRO 2 - Competências Digitais da Internet para idosos}

\begin{tabular}{|c|c|c|}
\hline \multicolumn{3}{|r|}{ Competências Digitais da Internet } \\
\hline Competências & $\begin{array}{l}\text { Competências } \\
\text { específicas }\end{array}$ & CHA (Conhecimentos, Habilidades, Atitudes) \\
\hline $\begin{array}{l}\text { Alfabetização } \\
\text { Digital }\end{array}$ & $\begin{array}{l}\text { Recursos } \\
\text { básicos da } \\
\text { Internet }\end{array}$ & $\begin{array}{l}\text {-Saber conceitos de internet, navegador e sites. } \\
\text {-Entrar na internet, identificar a barra de endereço da internet, digitar o } \\
\text { endereço e entrar em sites; } \\
\text {-Ter autonomia, autoconfiança e motivação para utilizar as ferramentas } \\
\text { da internet. }\end{array}$ \\
\hline $\begin{array}{l}\text { Alfabetização } \\
\text { Digital }\end{array}$ & $\begin{array}{l}\text { Pesquisa na } \\
\text { Internet }\end{array}$ & $\begin{array}{l}\text {-Saber sobre o conceito do que é uma pesquisa online e as ferramentas } \\
\text { disponíveis; } \\
\text {-Ser capaz de encontrar o campo para digitar as palavras e realizar uma } \\
\text { pesquisa. Analisar de forma crítica o resultado da busca; } \\
\text {-Ter motivação e autonomia para aprender sobre pesquisa online. }\end{array}$ \\
\hline $\begin{array}{l}\text { Alfabetização } \\
\text { Digital }\end{array}$ & $\begin{array}{l}\text { Comunicação } \\
\text { através do e- } \\
\text { mail }\end{array}$ & $\begin{array}{l}\text {-Saber o conceito de e-mail, netiqueta e anexo; } \\
\text {-Saber escrever um e-mail, escrever com cópia oculta, responder, abrir, } \\
\text { anexar e formatar o texto no e-mail. Aplicar netiqueta; } \\
\text {-Ter autonomia, responsabilidade e autoconfiança e motivação em } \\
\text { utilizar um e-mail. Analisar de forma crítica os e-mails recebidos }\end{array}$ \\
\hline $\begin{array}{l}\text { Letramento } \\
\text { Digital }\end{array}$ & $\begin{array}{l}\text { Informação } \\
\text { online } \\
\text { confiável }\end{array}$ & $\begin{array}{l}\text {-Saber sobre os perigos da internet e conceitos de segurança e } \\
\text { confiabilidade no virtual; } \\
\text {-Observar, analisar e criticar as informações online; } \\
\text {-Ter autonomia e autoconfiança e responsabilidade na analise crítica da } \\
\text { informação online. }\end{array}$ \\
\hline $\begin{array}{l}\text { Alfabetização } \\
\text { Digital } \\
\text { Letramento } \\
\text { Digital }\end{array}$ & $\begin{array}{l}\text { Resiliência } \\
\text { Virtual }\end{array}$ & $\begin{array}{l}\text {-Saber sobre as questões da velhice, entre elas os aspectos } \\
\text { biopsicossociais; } \\
\text {-Utilizar as limitações físicas e psicológicas ao seu favor; } \\
\text {-Reavaliar a sua atitude para continuar a aprender e utilizar o espaço } \\
\text { virtual. }\end{array}$ \\
\hline
\end{tabular}

Fonte: As autoras (2016). 
A proposta de desenvolver e/ou aprimorar competências de alfabetização digital, letramento digital e, por fim, fluência digital, bem como suas competências específicas só será possível se utilizar materiais pedagógicos diferenciados, juntamente com a adequação do tempo e ritmo próprio. Ou seja, a aprendizagem construída em cursos de inclusão digital de idosos é possível, mas se desenvolvida por uma metodologia que considere aspectos físicos, psicológicos, cognitivos e sociais dos idosos. Os autores Küller e Rodrigo (2013) apresentam alguns passos metodológicos que podem ser adotados, a partir deste mapeamento de competências digitais, em curso de inclusão digital de idosos: Contextualização e mobilização; Definição da atividade de aprendizagem; Organização da atividade de aprendizagem; Coordenação e acompanhamento; Análise e avaliação das atividades de aprendizagem; Acesso a outras referências e; Síntese e aplicação. Este é um possível exemplo de desenvolvimento das competências, existem outras que poderiam ser utilizadas e devem ser exploradas com este público.

\section{CONSIDERAÇÕES FINAIS}

Cada ano aumenta a população de pessoas com mais idade que iniciam a aprendizagem da informática. Ao mesmo tempo os espaços educacionais iniciam investigações em torno da construção da aprendizagem e desenvolvimento de competências digitais nestes cursos.

Este artigo teve como objetivo apresentar o mapeamento das competências digitais dos idosos no uso dos recursos da internet. Obteve-se neste mapeamento cinco competências específicas: Recursos básicos da Internet; Pesquisa na Internet; Informação online confiável; Comunicação através do e-mail; Resiliência virtual. Além do mapeamento destas competências também foi possível avaliar, de forma individual, os seus elementos (CHA) no intuito de analisar pontualmente as necessidades desta população na aprendizagem do computador, em específico dos recursos virtuais. Durante a análise dos elementos das competências observou-se um alto grau no que tange ao elemento atitude em todas competências, apontando que os idosos possuem motivação e interesse em aprender a utilizar os recursos da Internet. A limitação está no conhecimento sobre os recursos e a falta de habilidade em manusear tais tecnologias.

É necessário destacar que futuramente será analisada a influência, ou não, de outras competências específicas, e essenciais, na competência alfabetização digital, como o uso do teclado e mouse, a fim de verificar se há correlação nas médias apontadas nesta investigação.

Com este mapeamento é possível verificar que muito ainda há a ser investigado no que tange o uso do computador por idoso, principalmente o processo de resolução de problemas através do desenvolvimento e/ou aprimoramento de competências específicas. 


\section{REFERÊNCIAS}

AGUIAR, Eliane Vigneron Barreto; FLÔRES, Maria Lucia Pozzatti. Objetos de aprendizagem: conceitos básicos. In: TAROUCO, Liane Margarida Rockenbach; COSTA, Valéria Machado da; ÁVILA, Barbara Gorziza et al. Objetos de aprendizagem: teoria e prática. Porto Alegre: Evangraf, 2014. Disponível em: 〈http://goo.gl/XgpMHM〉. Acesso em: 14 mar. 2016.

BEHAR, Patricia Alejandra, RIBEIRO, Ana Carolina Ribeiro; SCHNEIDER, Daisy et al. Competências: conceito, elementos e recursos de suporte, mobilização e evolução. In: BEHAR, Patricia Alejandra (Org.). Competências em educação a distância. Porto Alegre: Penso, 2013, p. 20-41. Disponível em: 〈https://goo.gl/4JmnG6>. Acesso em: 14 mar. 2016.

CARVALHO, Glaucia Mauch de; TARALLO, Roberta dos Santos; BATISTONI, Samila Sathler Tavares et al. Redes sociais e geratividade: a experiência do programa idosos online. Estudos Interdisciplinares Sobre o Envelhecimento, Porto Alegre, RS, v. 19, n. 03, p. 793812. 2014. Disponível em: 〈http://goo.gl/VUsva8>. Acesso em: 14 mar. 2016. ISSN 23162171.

CENTRO DE ESTUDOS SOBRE AS TECNOLOGIAS DA INFORMAÇÃO E DA COMUNICAÇÃO. Pesquisa sobre o uso das tecnologias de informação e comunicação no Brasil: TIC domicílios e TIC empresas. São Paulo: Comitê Gestor da Internet no Brasil, 2014. 662 p. Disponível em: 〈http://goo.gl/n85xO3 >. Acesso em: 14 mar. 2016.

CAVALCANTE, Daniel do Nascimento e Sá; OLIVEIRA, André F.; RODRIGUES, Thiago O et al. A montanha vai a Maomé: uma abordagem para alfabetização digital de idosas de uma instituição de longa permanência. Computer On The Beach, Itajaí, SC, p. 498-500. 2015. Disponível em: 〈http://goo.gl/HqyrV7>. Acesso em: 12 jun. 2015. ISSN 2358-0852.

DEMO, Pedro. Inclusão digital - cada vez mais no centro da inclusão social. Inclusão Social, Brasília, DF, v. 01, n. 01, p. 36-38. out./mar. 2005. Disponível em: 〈http://goo.g1/2QVPR9>. Acesso em: 12 jun. 2015. ISSN 1808-8678.

DIAS, Isabel. O uso das tecnologias digitais entre os seniores: motivações e interesses. Sociologia, Problemas e Práticas, Lisboa, PT, n. 68, p. 51-77. 2012. Disponível em: <http://goo.gl/pvLrZs >. Acesso em: 12 jun. 2015. ISSN 2182-7907.

DOLL, Johannes; RAMOS, Anne Carolina; BUAES, Caroline Stumpf. Educação e envelhecimento. Educação \& Realidade, Porto Alegre, RS, v. 40, n. 01, p. 09-17. jan./mar. 2015. Disponível em: 〈http://goo.gl/ubELjD>. Acesso em: 14 mar. 2016. ISSN 2175-6236.

FILHO, Antonio Mendes da Silva. Os três pilares da inclusão digital. Revista Espaço Acadêmico, Maringá, PR, v. 03, n. 24. mai. 2013. Disponível em: <http://goo.gl/Paahth〉. Acesso em: 12 jun. 2015. ISSN 1519-6186.

FREIRE, Paulo. Educação e mudança. Rio de Janeiro: Paz e Terra. 1993.

GANDRA, Tatiane Krempser. Inclusão digital na terceira idade: um estudo de usuário na perspectiva fenomenológica. 2012. 137 f. Dissertação (Mestrado em Ciência da Informação) - Escola de Ciência da Informação, Universidade Federal de Minas Gerais, Belo Horizonte, MG, 2012. Disponível em: 〈http://goo.gl/qkFkpC>. Acesso em: 14 mar. 2016. 
KACHAR, Vitória. Terceira idade e informática: aprender revelando potencialidades. São Paulo: Cortez, 2003.

KACHAR, Vitória. Envelhecimento e perspectivas de inclusão digital. Revista Kairós Gerontologia, São Paulo, SP, v. 13, n. 02, p. 131-147. nov. 2010. Disponível em: <http://goo.gl/dtzyuB >. Acesso em: 14 mar. 2016. ISSN 2176-901X.

KÜLLER, José Antonio; RODRIGO, Natália de Fátima. Metodologia de desenvolvimento de competências. Porto Alegre: SENAC, 2013.

MACHADO, Leticia Rocha; BEHAR, Patricia Alejandra. Competências necessárias para os alunos idosos na educação a distância. In: BEHAR, Patrícia Alexandra (Org.). Competências em educação a distância. Porto Alegre: Penso, 2013, p. 223-236.

MACHADO, Leticia Rocha. Construção de uma arquitetura pedagógica para

cyberseniors: desvelando o potencial inclusivo da educação a distância. 2013. 190 f. Tese (Doutorado em Informática na Educação) - Centro Interdisciplinar de Novas Tecnologias na Educação, Universidade Federal do Rio Grande do Sul, Porto Alegre, RS, 2013. Disponível em: 〈http://goo.gl/HmlEzS $>$. Acesso em: 14 mar. 2016.

MACHADO, Letícia Rocha. Metas motivacionais de idosos em inclusão digital. 2007. 116 f. Dissertação (Mestrado em Gerontologia Biomédica) - Instituto de Geriatria e Gerontologia, Pontifícia Universidade Católica do Rio Grande do Sul, Porto Alegre, RS, 2007. Disponível em: 〈http://goo.gl/MFzaHn>. Acesso em: 14 mar. 2016.

MARTÍN, Antonio Víctor. Gerontologia educativa: enquadramento disciplinar para o estudo e intervenção socioeducativo com idosos. In: OSORIO, Agustin Requejo; PINTO, Fernando Cabral. As pessoas idosas: contexto social e intervenção educativa. Lisboa: Instituto Piaget, 2007.

PEREIRA, Claudia; NEVES, Rui. Os idosos e as TIC - competências de comunicação e qualidade de vida. Revista Kairós Gerontologia, São Paulo, SP, v. 14, n. 01. mar. 2011. Disponível em: 〈http://goo.gl/JimbkS>. Acesso em: 14 mar. 2016. ISSN 2176-901X.

PERRENOUD, Philippe. Construir as competências desde a escola. Porto Alegre: Artmed, 1999.

PERRENOUD, Philippe. Desenvolver competências ou ensinar saberes? A escola que prepara para a vida. Porto Alegre: Penso, 2013.

PETRELLA, Simone; PINTO, Manuel; PEREIRA, Sara. O idoso e a educação para os Media. Novos desafios entre envelhecimento e exclusão social. In: SOPCOM COMUNICAÇÃO GLOBAL, CULTURA E TECNOLOGIA, 8., 2014, p. 150-155. Anais eletrônicos... Disponível em: 〈http://goo.gl/yJdWwN>. Acesso em: 12 jun. 2015.

PEREIRA, Claudia; NEVES, Rui. Os idosos na aquisição de competências TIC. Educação, Formação \& Tecnologias, Minho, PT, v. 04, n. 02, p. 15-24. nov. 2011. Disponível em: < http://goo.gl/PlcFTJ>. Acesso em: 14 mar. 2016. ISSN 1646-933X. 
PINHO, José Antônio Gomes de. Participação social na internet: reflexões sobre os caminhos para a criação de competências infocomunicacionais na realidade brasileira. In: BORGES, Jussara; JAMBEIRO, Othon et al (Org.). In: SEMINÁRIO DE COMPETÊNCIAS INFOCOMUNICACIONAIS E PARTICIPAÇÃO SOCIAL. Anais eletrônicos... Salvador: UFBA, 2012. 59 p. Disponível em: 〈https://goo.gl/Rs0d4U〉. Acesso em: 14 mar. 2016.

SALES, Marcia Barros; MARIANI, Antonio Carlos; ALVARES, Angela Maria. Informática para a 3 $3^{\mathbf{a}}$ idade. Rio de Janeiro: Ciência Moderna, 2009. 136p.

SANTOS, Hemanuela Fernandes Mello dos. Competência digital: uma vertente da competência informacional. 2008. 50 f. Monografia (Graduação em Biblioteconomia) Centro de Ciências Sociais Aplicadas, Universidade Federal do Rio Grande do Norte, Natal, RN, 2008. Disponível em: 〈http://goo.gl/6xr8At >. Acesso em: 14 mar. 2016.

SCORALICK-LEMPKE, Natália Nunes; BARBOSA, Altemir José Gonçalves; MOTA, Márcia Maria Peruzzi Elia. Efeitos de um processo de alfabetização em informática na cognição de idosos. Psicologia: Reflexão Crítica, Porto Alegre, RS, v. 25, n. 04, p. 774-782. 2012. Disponível em: 〈http://goo.gl/X8JB8r>. Acesso em: 14 mar. 2016. ISSN 0102-7972.

SILVA, Tiago Rodrigo da; BUZ, Diego Fernandes; PESSOA, Nádia Soraida Mateus. Inclusão digital da terceira idade. Anais SULCOMP, Criciúma, SC, v. 07. 2014. Disponível em: 〈http://goo.gl/lKgiwC>. Acesso em: 14 mar. 2016. ISSN 2359-2656.

SILVEIRA, Michele Marinho da; KÜMPEL, Daiana Argenta; ROCHA, Josemara de Paula et al. Processo de aprendizagem e inclusão digital na terceira idade. Revista Tecnologia e Sociedade, Curitiba, PR, v. 07, n. 13, p. 106-117. 2011. Disponível em: <https://goo.gl/7MERcu>. Acesso em: 14 mar. 2016. ISSN 1984-3526.

TAVARES, José. (Org.) Resiliência e educação. São Paulo: Cortez, 2001.

TONI, Isabel Marrachinho. Educação e psicologia: interações e estratégias para uma velhice bem sucedida. In: CASARA, Miriam Bonho; CORTELLETTI, Ivonne Assunta; BOTH, Agostinho. Educação e envelhecimento. Caxias do Sul: Educa, 2006.

VECHIATO, Fernando Luiz. Repositório digital como ambiente de inclusão digital e social para usuários idosos. 2010. 185 f. Dissertação (Mestrado em Ciência da Informação) - Faculdade de Filosofia e Ciências, Universidade Estadual Paulista Júlio de Mesquita Filho, Marília, SP, 2010. Disponível em: 〈https://goo.gl/u48WTT>. Acesso em: 14 mar. 2016. 
LETICIA ROCHA MACHADO

Doutora em Informática na Educação Universidade Federal do Rio Grande do Sul - UFRGS

Porto Alegre, RS - Brasil

E-mail: leticiarmachado@yahoo.com.br

TÁSSIA PRISCILA FAGUNDES GRANDE Especialista em Psicopedagogia e TICs - Modalidade EAD

Universidade Federal do Rio Grande do Sul - UFRGS Porto Alegre, RS - Brasil

Mestranda em Educação

Universidade Federal do Rio Grande do Sul - UFRGS

Porto Alegre, RS - Brasil

E-mail: tpri.fagundes@hotmail.com

PATRICIA ALEJANDRA BEHAR Doutora em Computação

Universidade Federal do Rio Grande do Sul - UFGRS Porto Alegre, RS - Brasil

Professora titular do Departamento de Estudos Especializados Universidade Federal do Rio Grande do Sul - UFGRS Porto Alegre, RS - Brasil E-mail:pbehar@terra.com.br

FABIANA DE MIRANDA ROCHA LUNA

Graduação em Pedagogia

Universidade Federal do Rio Grande do Sul - UFGRS

Porto Alegre, RS - Brasil

E-mail: fabiana.mrocha@terra.com.br

Recebido em: 14/03/2016

Aprovado para publicação em: 26/04/2016

\section{Como citar este documento:}

MACHADO, Leticia Rocha; GRANDE, Tássia Priscila Fagundes; BEHAR, Patricia Alejandra; LUNA, Fabiana de Miranda Rocha. Mapeamento de competências digitais: a inclusão social dos idosos. ETD - Educação Temática Digital, Campinas, SP, v. 18, n. 4, p. 903-921, set. 2016. ISSN 1676-2592. Disponível em: <http://periodicos.sbu.unicamp.br/ojs/index.php/etd/article/view/8644207>. Acesso em: 16 nov. 2016. doi:http://dx.doi.org/10.20396/etd.v18i4.8644207. 